\title{
CRYSTAL PLASTICITY FINITE ELEMENT SIMULATIONS OF THE INDENTATION TEST ${ }^{1}$
}

\author{
KAROL FRYDRYCH* \\ Institute of Fundamental Technological Research, Polish Academy of Sciences, \\ Pawińskiego 5B, 02-106 Warsaw, Poland \\ ${ }^{*}$ Corresponding author: kfryd@ippt.pan.pl
}

\begin{abstract}
The goal of the paper is to report the successful simulations of the nanoindentation problem. The finite-strain isotropic elasto-plasticity and crystal elasto-plasticity models used for the simulations are described. The developed contact formulation describing the contact with rigid surface approximating pyramidal indenter is presented. Both tensile stress-strain and indentation load-penetration curves obtained with a single set of material parameters are presented to be in the satisfactory agreement with experimental data. It seems that such a result is presented for the first time.
\end{abstract}

Key words: crystal plasticity; indentation; Al 6061-T6; nanoindentation; Vickers; Berkovich; CPFEM

\section{INTRODUCTION}

The changes of microstructure and mechanical properties of materials subjected to irradiation occurring in nuclear reactors are still not fully understood. Instead of complicated tests on irradiated (and thus radioactive) samples, ion implantation can serve as a tool to analyse the irradiation effects. However, the layer implanted with ions is typically very thin. Therefore, in such a case, the traditional testing methods cannot be used and nanoindentation has to be applied, cf. e. g. (Hosemann et al., 2009; Hosemann et al., 2012; Kucharski \& Jarząbek, 2014). Unfortunately, there is no robust method to link the forcepenetration curve obtained in the nanoindentation to the stress-strain curves obtained in tensile tests, especially in the plastic range. Therefore there is a need to directly model the indentation test, e.g. using the finite element method (FEM).

The effect of the shape of the pyramidal indenter was analysed in (Berla et al., 2010; Torres-Torres et al., 2010). In the first article the function approximating the three-sided pyramidal indenter was proposed. This axisymmetric function is constructed by a combination of a paraboloid and a cone. However, the authors did not use their function to perform any FE simulation and showed the validity of their approach using phenomenological equations describing characteristic features of the indentation test. In the second paper the effect of the bluntness of the tip was studied using the FEM in the framework of macroscopic elasto-plasticity. The shape of the Berkovich indenter was both modelled in a simplified fashion as a cone in a $2 \mathrm{D}$ axisymmetric problem and exactly as a pyramid in a 3D simulation. The bluntness was introduced by rounding the sharp tip of the indenter. For both 2D and 3D simulations, it was found that introducing bluntness of the geometry is very important to correctly predict the parameters of the material as the load required to obtain a given penetration considerably increases in case of simulations with rounded tip.

${ }^{1}$ The paper presented during YIC 2019, ECCOMAS Young Investigators Conference held in Kraków, Poland on September 1-6, 2019 
So far, there were numerous papers dealing with simulations of indentation in the framework of the crystal plasticity finite element method (CPFEM). Wang et al. (2004) performed experiments and modelling of nanoindentation of single crystals and focused on studying the dependence of the pile-up patterns on the crystallographic orientation. In order to avoid the complications stemming from simultaneous effect of both crystallographic and indenter's symmetry, the conical indenter was used. The authors failed to correctly predict the load-penetration curves - moreover they claimed the difference with experimental data was more than an order of magnitude.

CPFEM simulations for sphero-conical indenter tip were presented in ( $\mathrm{Li}$ et al., 2013; Zambaldi \& Raabe, 2010; Zambaldi et al., 2012). Many research was also devoted to modelling the spherical indentation. Liu et al. $(2005 ; 2008)$ obtained good agreement between experimental data and both the pile-up patterns and load-penetration curves in spherical nanoindentation of copper single crystals. However, their prediction of the orientation dependence of the loadpenetration curves cannot be treated as correct, especially for the lower value of the indenter's radius, $\mathrm{cf}$. figure 5 in (Liu et al., 2008). Interestingly, the authors used different friction coefficients for various crystallographic orientations, in order to obtain correct pileup profiles. The spherical indentation was simulated also in (Alcalá et al., 2015; Casals \& Forest, 2009; Chang et al., 2010; Kucharski et al., 2014; Lewandowski \& Stupkiewicz, 2018; Petryk et al., 2017).

As concerns the pyramidal indenters, they were mostly modelled by exact representation of their geometry, with or without considering the roundness of their tips and edges. The exact geometry of the Vickers indenter was modelled in (Alcalá et al., 2008; Eidel, 2011). The exact geometry of the Berkovich indenter was modelled in (Alcalá et al., 2008; Alcalá et al., 2015; Liu et al., 2014; Liu et al., 2015; Liu et al., 2016; Renner et al., 2016; Saleh et al., 2016; Wang et al., 2019; Wang et al., 2018; Xiao et al., 2019a; Yao $\&$ You, 2017). In (Renner et al., 2016) the indenter was meshed and assumed to be a rigid body. Frictionless contact was prescribed. The parameters of the model were calibrated using the comparison with nanoindentation test and validated in simulation of the tensile test performed on the representative volume element (RVE). Wang et al. (2018) also performed the CPFEM simulations with exact geometry of the Berkovich indenter, which was modelled including the roundness of its tip. Friction coefficient was set equal to 0.1 . The authors showed both experimental and simulated load-penetration curves. However, they failed to predict the slight differences in the experimental curves stemming from different crystallographic orientations (cf. figure 3 in (Wang et al., 2018)). The study nicely showed the combined effect of the crystallographic orientation and indenter's geometry. The exact geometry of the Berkovich indenter was modelled also in CPFEM simulations of Yao and You (2017). The research shows that there is a negligible effect of the crystallographic orientation upon the load-penetration curves, both in case of the experiment and the simulation.

This paper is devoted only to the CPFEM simulations of the indentation applied to ,virgin” (i.e. not irradiated) material. However, the ultimate goal is to use the simulation framework as a tool to validate constitutive models for ion irradiated materials. The modelling of irradiation effects in the framework of macroscopic plasticity was presented in (Ryś, 2016; Ryś \& Skoczeń, 2017; Skoczeń \& Ustrzycka, 2015; Skoczeń \& Ustrzycka, 2016). Treatment of the irradiation-driven effects in the framework of crystal plasticity (CP) theory was reported e. g. in (Hure et al., 2016; Ling et al., 2017; Nie et al., 2018). Recently, in some papers the modelling of the nanoindentation including the irradiation effects was reported, cf. (Saleh et al., 2016; Wang et al., 2019; Xiao et al., 2019a, Xiao et al., 2019b).

The paper is structured as follows. After this introductory section, the modelling framework concerning both plasticity models used and the implemented contact formulation is presented. Then the results of the nanoindentation simulations are shown. They are compared against experimental data. Finally, some discussion and conclusions follow.

\section{MODELLING}

The AceGen/AceFEM software (Korelc, 1996, 1997; 2002; Korelc \& Wriggers, 2016) is applied. Both the CPFEM and contact elements are implemented using the AceGen software. The AceGen software is a very efficient tool enabling the generation of the numerical codes from the symbolic input. It takes advantage of the automatic differentiation and expression optimization techniques. The AceFEM software is used to conduct the finite element simulations. Finite element problem is efficiently solved using the Intel MKL PARDISO solver. 


\subsection{Plasticity}

In order to compare the CPFEM simulations against a simpler finite-strain elasto-plastic model the SED3H1DFJCH1DNeoHookeWAMisesExH element from the AceFEM library is used. In this model the deformation gradient $\mathrm{F}$ is multiplicatively decomposed into elastic and plastic parts:

$$
\mathbf{F}=\mathbf{F}_{e} \mathbf{F}_{p}
$$

The elastic strain energy is calculated as follows:

$$
W=\frac{1}{2} \mu\left(I_{1}-3-\log I_{3}\right)+\frac{1}{4} \lambda\left(I_{3}-1-\log I_{3}\right)
$$

where: $\mu$ and $\lambda$ are Lamé constants, $\mathbf{b}_{e}$ is the left elastic Cauchy-Green tensor: $\mathbf{b}_{e}=\mathbf{F}_{e} \mathbf{F}_{e}^{T}$ and $I_{1}=\operatorname{tr} \mathbf{b}_{e}, I_{3}$ $=\operatorname{detb}_{e}$

The Cauchy stress tensor $\boldsymbol{\sigma}$ and Kirchhoff stress $\boldsymbol{\tau}$ are computed using the following equations:

$\boldsymbol{\sigma}=\frac{\boldsymbol{\tau}}{\operatorname{det} \mathbf{F}}=\frac{2}{\operatorname{det} \mathbf{F}} \mathbf{b}_{e} \frac{\partial W}{\partial \mathbf{b}_{e}}$

As concerns the plasticity, the standard J2 plasticity with linear hardening is applied. The HuberMises-Hencky equivalent stress is calculated as follows:

$$
\sigma_{H M H}=\sqrt{\frac{3}{2} \operatorname{tr}(\mathbf{s . s})}=\sqrt{3 J_{2}}
$$

Where: $\mathbf{s}=\operatorname{dev} \boldsymbol{\sigma}$.

As concerns the plasticity, the standard $J_{2}$ plasticity with linear hardening is applied. The HuberMises-Hencky equivalent stress is calculated as follows:

$$
\sigma_{y}=\sigma_{y 0}+H \gamma^{p}
$$

Where: $\sigma_{y 0}$ is an initial yield stress, $H$ is the linear hardening parameter and $\gamma^{p}$ is the accumulated plastic deformation. The yield surface is described by the equation:

$$
\mathcal{F}(\boldsymbol{\sigma})=\sigma_{\text {HМH }}-\sigma_{y}
$$

The associated flow rule:

$$
\mathbf{D}_{p}=\lambda \frac{\partial \mathcal{F}}{\partial \boldsymbol{\tau}}
$$

governs the evolution of the plastic part of the rate of deformation tensor $\mathbf{D}_{p}$. The plastic multiplier is equivalent to the accumulated plastic deformation $\gamma^{p}$. It is computed so as fulfil the Karush-Kuhn-Tucker (KKT) conditions: $\lambda \geq 0 \wedge \mathcal{F} \leq 0 \wedge \dot{\lambda} \mathcal{F}=0$

The inverse of the right plastic Cauchy-Green tensor $\mathbf{C}_{p}^{-1}$ is updated using the exponential map:

$\mathbf{F} \dot{\mathbf{C}}_{p}^{-1}=-2 \mathbf{D}^{p} \mathbf{F} \mathbf{C}_{p}^{-1} \rightarrow \mathbf{F C}_{p}^{-1}(t+\Delta t)=\exp \left(-2 \mathbf{D}^{p}\right) \mathbf{F C}_{p}^{-1}(t)$

The 8-noded linear brick element is used for the simulations presented here.

\subsection{Crystal Plasticity Finite Element Method}

The applied crystal plasticity model formulation follows the classical ideas (Asaro \& Needleman, 1985; Asaro \& Rice, 1977; Hill \& Rice, 1972). The implemented formulation is the finite-strain rate-independent crystal elasto-plasticity model (Arminjon, 1991; Gambin, 1991, Kowalczyk \& Gambin, 2004) that was already applied e.g. in (Frydrych \& Kowalczyk-Gajewska, 2018; Frydrych et al., 2019; Kucharski et al., 2014). Again, the multiplicative decomposition of the deformation gradient is applied (equation 1). Hyperelastic formulation is used in order to calculate the Mandel stress $\mathbf{M}_{e}=\mathbf{F}_{e}^{T} \mathbf{S F}_{p}^{T}$ (Mandel, 1971):

$\mathbf{M}_{e}=2 \mathbf{C}_{e} \frac{\partial \Psi}{\partial \mathbf{C}_{e}}$

where: $\mathbf{C}_{e}=\mathbf{F}_{e}^{T} \mathbf{F}_{e}$ is the right elastic Cauchy-Green tensor and the free energy density per unit volume in reference configuration is calculated using the elastic Lagrangian strain tensor $\mathbf{E}_{e}=\frac{1}{2}\left(\mathbf{C}_{e}-\mathbf{1}\right)$ :

$\Psi=\frac{1}{2} \mathbf{E}_{e} \cdot \mathbb{L}^{e} \cdot \mathbf{E}_{e}$

and $\mathbb{L}^{e}$ is the anisotropic stiffness tensor of a single crystal.

The plastic part of the deformation gradient is updated using the exponential mapping:

$\dot{\mathbf{F}}_{p}=\hat{\mathbf{L}}_{p} \mathbf{F}_{p} \rightarrow \mathbf{F}_{p}(t+\Delta t)=\exp \left(\Delta t \mathbf{L}_{p}\right) \mathbf{F}_{p}(t)$

where: the plastic part of the velocity gradient $\mathbf{L}_{p}$ is a sum of shears on crystallographic slip systems:

$\mathbf{L}^{p}=\sum_{r=1}^{M} \dot{\gamma}^{r} \mathbf{m}_{0}^{r} \otimes \mathbf{n}_{0}^{r}$

where: $\left\{\mathbf{m}_{0}^{r}, \mathbf{n}_{0}^{r}\right\}$ are the direction and plane normal of the slip system $r$ in the initial configuration. 
The regularized yield surface of the single crystal:

$$
\mathcal{F}(\boldsymbol{\sigma})=\left(\sum_{r}\left(\frac{\tau^{r}}{\tau_{c}^{r}}\right)^{2 n}\right)^{1 /(2 n)}-1
$$

is used to obtain the plastic multiplier $\dot{\lambda}$ from the KKT conditions (equation (8)).

The associated flow rule is used to obtain the rate of shearing $\dot{\gamma}$ on a slip system $r$ :

$$
\dot{\gamma}^{r}=\dot{\lambda} \frac{1}{\tau_{c}^{r}}\left(\frac{\tau^{r}}{\tau_{c}^{r}}\right)^{2 n-1}
$$

Similarly as in the conventional plasticity model, the 8-noded linear brick element is used for the simulations presented here.

\subsection{Contact formulation}

The pyramidal indenter is approximated using the function:

$$
f(x, y)=\sqrt{\frac{x^{2}}{a^{2}}+\frac{y^{2}}{a^{2}}+\delta^{2}}-\delta,
$$

which can be visualized as shown in figure 1 .

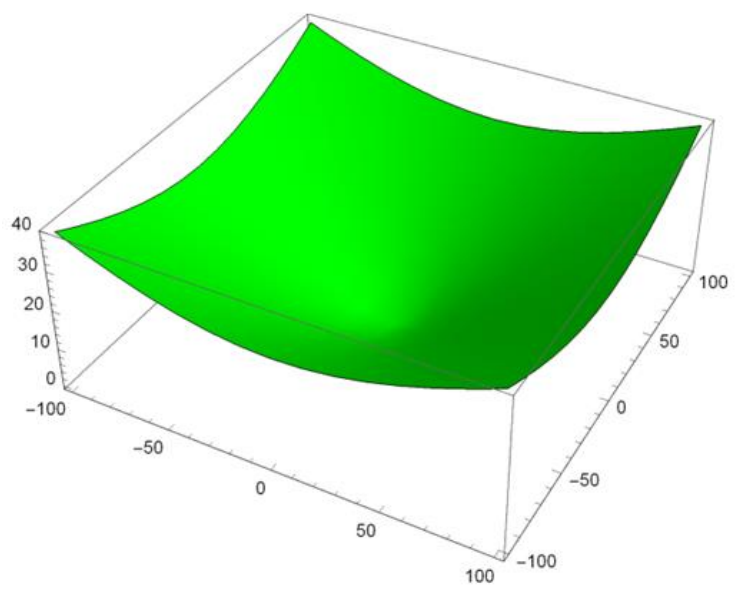

Fig. 1. The approximation of pyramidal indenter using the function $f(x, y)$ given in equation (16). The parameters $a$ and $\delta$ in this plot are equal to 3.22 and 5 , respectively.

The equation is based on the equation of the cone and thus the parameter $a$ describes the slope of its side. The second parameter, $\delta$ is introduced under the square root in order to obtain rounded tip of the cone. Basically, the higher the delta, the larger the radius of the rounded tip is. With $\delta=0$, the equation of the cone is restored. The parameter $\delta$ appears also outside the square root in order to make sure that the surface has its ,origin” in point $(0,0,0)$. In the preliminary studies, it was established that using such a function can lead to force-displacement predictions with satisfactory agreement with the experimental data for both Vickers and Berkovich indenters. Here, the comparison with the Vickers indenter is reported.

The contact element is implemented following the framework presented in (Lengiewicz, 2008; Stupkiewicz et al., 2010). The surface of the indenter is treated as a rigid body. The topology of the contact element is the quadrilateral with 4 nodes in $3 \mathrm{D}$ ( $\mathrm{S} 1$ in the nomenclature of AceFEM). The Lobatto quadrature is applied. The local contact search is applied to find the projection of each slave node onto the rigid master surface. The augmented Lagrange multipliers (see quations (41) and (58) in (Stupkiewicz et al., 2010)) are used to ensure the exact fulfilment of the contact constraints - the impenetrability condition:

$g_{N} \geq 0 \wedge t_{N} \leq 0 \wedge t_{N} g_{N}=0$,

and the Coulomb friction law:

$\Phi=\left\|\mathbf{t}_{T}\right\|+\mu t_{N} \leq 0 \wedge\left\|\dot{\mathbf{g}}_{T}\right\| \mathbf{t}_{T}=\dot{\mathbf{g}}_{T}\left\|\mathbf{t}_{T}\right\| \wedge \Phi\left\|\dot{\mathbf{g}}_{T}\right\|=0$

Where: $g_{N}-$ normal gap, $t_{N}$ - contact pressure, $\mu-$ friction coefficient, $\dot{\mathbf{g}}_{T}-$ slip velocity and $\mathbf{t}_{T}-\tan$ gential traction vector.

\subsection{Contact formulation}

Hanging nodes formulation is an old and simple concept and in this particular application it consists in enforcing the displacements of the nodes of the twice refined mesh to be consistent with the displacements of the neighbouring coarse mesh. This is done with the help of additional quadratic quadrilateral elements on the interface between coarse and fine mesh. The displacements of the additional nodes (on edges and in the center of the element) are constrained to be such that the quadratic element behaves as a linear one. With $u_{c 1}, u_{c 2}$ and $u_{\text {hanging }}$ defined as in figure 2 , the constraint for each hanging node is introduced:

$u_{\text {hanging }}=\frac{1}{2} u_{c 1}+\frac{1}{2} u_{c 2}$.

Analogously, the constraint of the hanging node in the center of the quadrilateral element is:

$u_{\text {hanging }}=\frac{1}{4} u_{c 1}+\frac{1}{4} u_{c 2}+\frac{1}{4} u_{c 3}+\frac{1}{4} u_{c 4}$.

The constraints are enforced using the augmented Lagrangian formulation. 


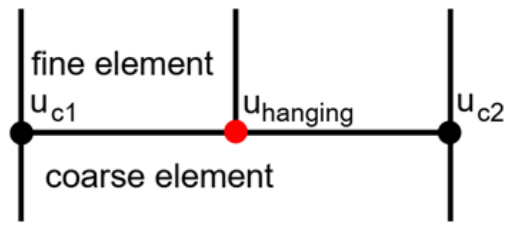

Fig. 2. The hanging node concept.

\section{CALIBRATION OF PARAMETERS}

The isotropic elastic constants of Al 6061-T6 alloy considered here are taken to be the same as in the yet unpublished paper reporting experimental nanoindentation experiment. The single crystal elastic constants are taken from table 1 in (Thomas Jr, 1968). In order to calibrate the parameters of both plasticity models, the tensile test was simulated. The parameters of the isotropic elasto-plastic model described in section 2.1 are shown in table 1 , while the parameters of the crystal elasto-plastic model described in section 2.2 are shown in table 2. The resulting stress-strain curves are shown in figure 3 . In case of the CPFEM simulation, 27 random orientations in a mesh (1 element per grain) were considered. The displacement boundary conditions were used. It has been verified that this number of grains and level of discretization was sufficient in order to identify the material model parameters. Excellent agreement with the experimental data of (Ambriz et al., 2011) is achieved.

Table 1. The parameters of the finite strain isotropic elasto-plastic model.

\begin{tabular}{|c|c|c|c|}
\hline $\begin{array}{c}E \\
\mathrm{GPa}\end{array}$ & $v$ & $\begin{array}{c}\sigma_{y 0} \\
\mathrm{GPa}\end{array}$ & $\begin{array}{c}H \\
\mathrm{GPa}\end{array}$ \\
\hline 69 & 0.26 & 0.305 & 0.5 \\
\hline
\end{tabular}

Table 2. The parameters of the finite strain crystal elasto-plastic model.

\begin{tabular}{|c|c|c|c|c|c|c|c|c|}
\hline$C_{11}$ & $C_{12}$ & $C_{44}$ & $\tau_{0}$ & $\tau_{1}$ & $\theta_{0}$ & $\theta_{1}$ & $q$ & $n$ \\
$\mathrm{GPa}$ & $\mathrm{GPa}$ & $\mathrm{GPa}$ & $\mathrm{GPa}$ & $\mathrm{GPa}$ & $\mathrm{GPa}$ & $\mathrm{GPa}$ & & \\
\hline 106.7 & 60.4 & 28.3 & 0.12 & 0.02 & 0.1 & 0.006 & 1.4 & 10 \\
\hline
\end{tabular}

\section{RESULTS}

The nanoindentation is simulated as follows. It is assumed that the size of the indenter is small compared to the average grain size and therefore only single crystals are simulated. That is, the same crystallographic orientation is specified across the whole computational domain.

The mesh for the least refined case is presented in figure 4. The dimensions of the domain are $360 \times 360 \times 180 \mu \mathrm{m}$ while the most refined region has dimensions $120 \times 120 \times 30 \mu \mathrm{m}$. The contact elements are present only on the surface of the most refined region. In order to enable double refinement of the layer closest to the surface, the hanging nodes (see section 2.4) are used. The parameters of the contact function $f(x, y)$ (equation (16)) are equal to: $a=2.48$ and $\delta=$ 0.005 . According to the literature, the effect of friction has very little effect upon the simulated loadpenetration curves (Casals \& Forest, 2009; Liu et al., 2005; Wang et al., 2004). This was also confirmed is numerical studies of the present author. Therefore, frictionless contact is assumed.

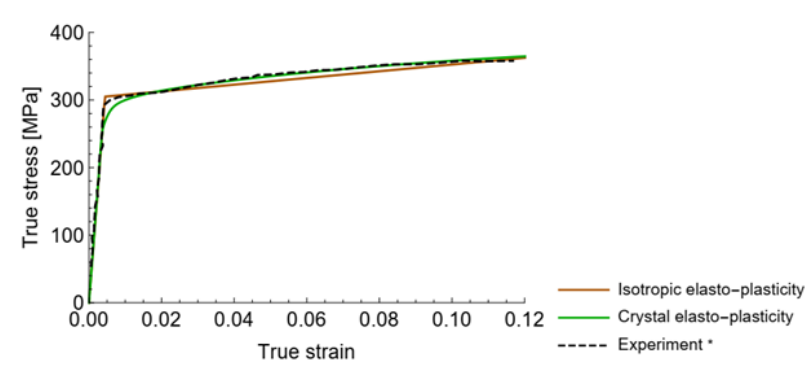

Fig. 3. The stress-strain curves. The experimental data are taken from (Ambriz et al., 2011).

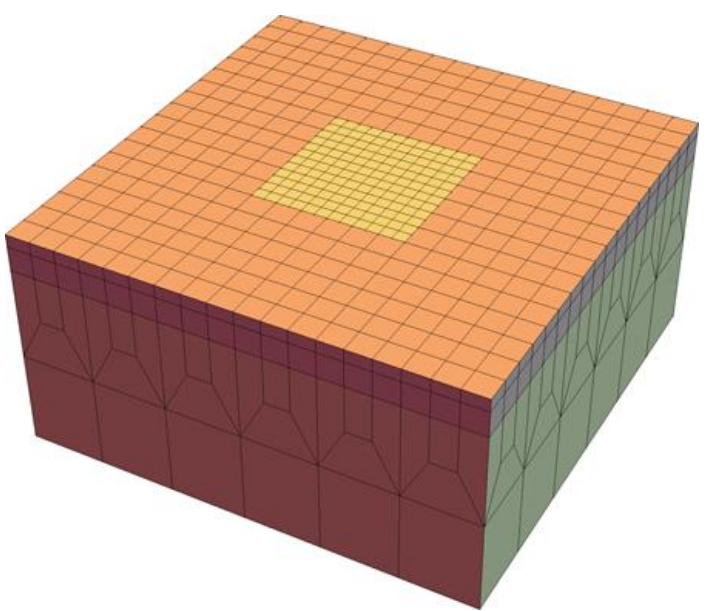

Fig. 4. The least refined mesh $(12 \times 12$ contact elements $)$ used for simulations of nanoindentation.

The load-penetration curves for various mesh refinements are shown in figure 5 . It can be seen that the mesh with $48 \times 48$ contact elements can be treated as converged - the results do not differ much from the $72 \times 72$ mesh. In figure 5 also the experimental result taken from (Ambriz et al., 2011) is plotted. It can be seen that the simulated results are in a reasonable agreement with the experimental data. At first glance it may seem that the standard elastoplastic model behaves better than the crystal elasto-plastic model. Indeed, the stress-strain curves in case of the coarse meshes are closer to the experimental one for the isotropic elasto-plastic model. However, for the converged meshes $(48 \times 48$ and $72 \times 72)$ the agreement is 
actually slightly better for the crystal plasticity solution. Specifically, for the $48 \times 48$ mesh the value of the force for maximal penetration is $821.2 \mathrm{mN}$ in case of the elasto-plastic model while it is $830.3 \mathrm{mN}$ in case of the crystal plasticity model. In case of the $72 \times 72$ mesh these values are respectively $822.2 \mathrm{mN}$ and $829.4 \mathrm{mN}$.

It should be stressed that the parameters of both models were calibrated so as to produce correct tensile stress-strain curves and excellent agreement was achieved in that case. Despite reviewing many papers (see section 1), the author has not found any article, where both tensile stress-strain and indentation load penetration curves were shown to be produced with the same set of parameters. Here, it is done, and only a small deviation with respect to the experimental data is observed.

According to (Alcalá et al., 2008), simulated load-penetration curves have very little sensitivity to the crystallographic orientation regardless of the $\mathrm{CP}$ model. This is confirmed in the present study, see figure 6. It was also shown in the literature (e. g. (Wang et al., 2004)) that the orientation significantly affects the shape of the pile-ups around the indent. The predicted pile-ups for the three orientations are shown in figure 7. The simulation predicted the four-, two- and three-fold symmetry of the pile-up pattern for the (001), (011) and (111) indented planes which is in agreement with experimental and numerical studies of axisymmetric indentation of other researchers (e. g. (Wang et al., 2004)).
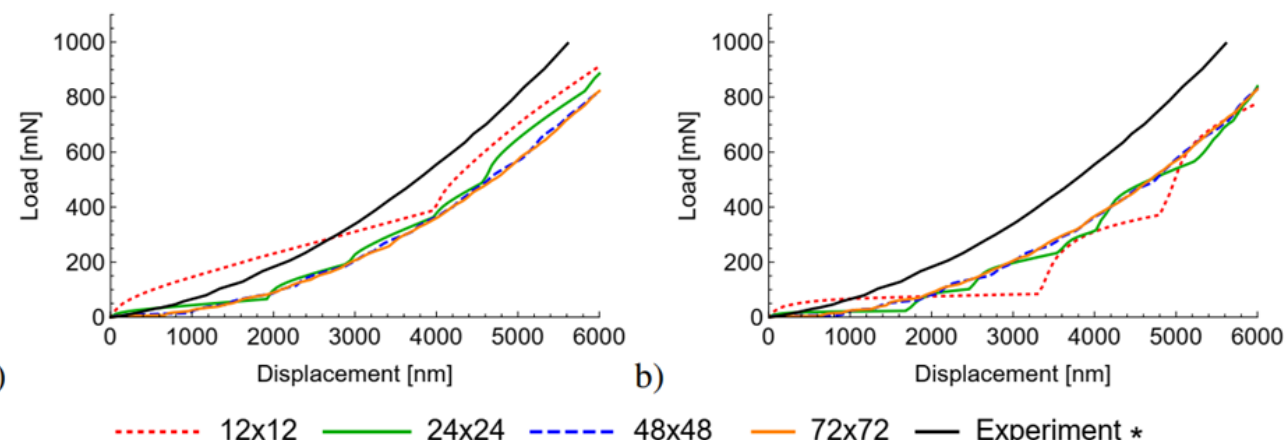

Fig. 5. The load penetration curves obtained using a) isotropic elasto-plastic and b) crystal elasto-plastic models. Experimental data taken from (Ambriz et al., 2011) are also shown.

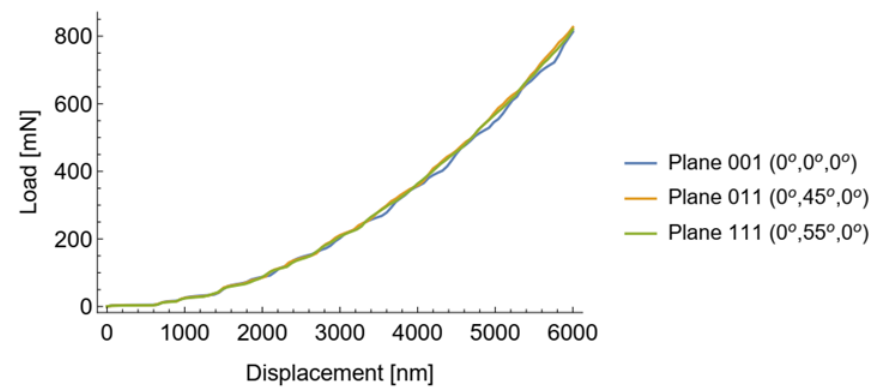

Fig. 6. The load penetration curves for three different crystallographic orientations. The angles are the Euler angles in the Bunge convention.

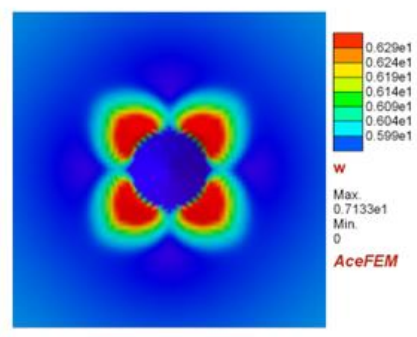

Plane (001)

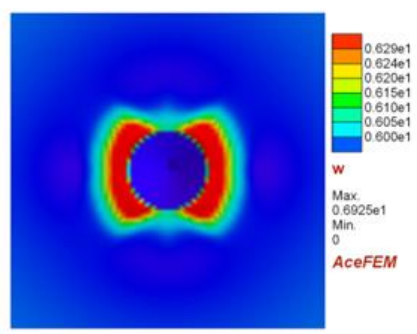

Plane (011)

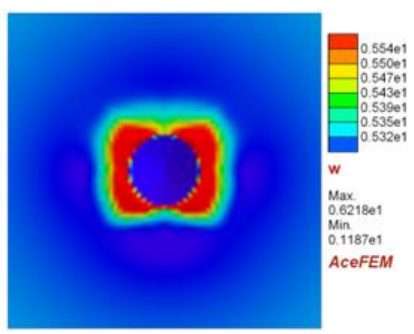

Plane (111)

Fig. 7. The shapes of the pile-ups for three different crystallographic orientations. The color code denotes the amount of vertical displacement. In the simulation the position of the indenter is fixed and the deformed material moves upward. Therefore zero vertical displacement is present under the tip of the indenter. 


\section{SUMMARY AND CONCLUSIONS}

To sum up:

- New function that can approximate the shape of a pyramidal indenter has been implemented in the contact element formulation.

- The contact element has been used for the CPFEM simulations.

- The parameters calibrated using experimental tensile stress-strain curves enabled to obtain satisfactory agreement with experimental load-penetration curves and pile-up patterns.

- To the best of author's knowledge, this is the first study where both tensile stress strain curves and indentation load penetration curves obtained with a single set of parameters were presented, and where the agreement with experimental data was satisfactory.

- With the developed modelling framework, validation of constitutive models of irradiated materials can be performed in the future.

\section{ACKNOWLEDGMENTS}

The research is supported from the National Science Center, Poland (project no. 2016/23/B/ST8/ 03418). Prof. Stanisław Stupkiewicz from IPPT is acknowledged for his help in the implementation of the contact element. Prof. Katarzyna KowalczykGajewska is acknowledged for the verification of the equations. Dr. Aneta Ustrzycka from IPPT is acknowledged for fruitful discussions and sharing her experimental results.

\section{REFERENCES}

Alcalá, J., Casals, O., Očenášek, J., 2008, Micromechanics of pyramidal indentation in fcc metals: Single crystal plasticity finite element analysis, J. Mech. Phys. Solids, 56(11), 32773303.

Alcalá, J., Esqué-de los Ojos, D., Očenášek, J., 2015, Extracting uniaxial responses of single crystals from sharp and spherical hardness measurements, Mech. Mater., 84, 100-113.

Ambriz, R., Chicot, D., Benseddiq, N., Mesmacque, G., De La Torre, S., 2011, Local mechanical properties of the 6061-T6 aluminium weld using micro-traction and instrumented indentation, European Journal of Mechanics- A/Solids, 30(3), 307-315.

Arminjon, M., 1991, A regular form of the Schmid law. Application to the ambiguity problem, Textures and Microstructures, 14-18, 1121-1128.
Asaro, R.J., Needleman, A., 1985, Texture development and strain hardening in rate dependent polycrystals, Acta Metall., 33(6), 923-953.

Asaro, R.J., J., Rice, R., 1997, Strain localization in ductile crystals, J. Mech. Phys. Solids, 25, 309-338.

Berla, L.A., Allen, A.M., Han, S.M., Nix, W.D., 2010, A physically based model for indenter tip shape calibration for nanoindentation, J. Mater. Res., 25(4), 735-745.

Casals, Q., Forest, S., 2009, Finite element crystal plasticity analysis of spherical indentation in bulk single crystals and coatings, Comput. Mater. Sci., 45(3), 774-782.

Chang, H.-J., Fivel, M., Rodney, D., Verdier, M., 2010, Multiscale modelling of indentation in fcc metals: From atomic to continuum, Comptes Rendus Physique, 11(3-4), 285-292.

Eidel, B., 2011, Crystal plasticity finite-element analysis versus experimental results of pyramidal indentation into $\left(\begin{array}{lll}0 & 0 & 1\end{array}\right)$ fcc single crystal, Acta Mater., 59(4), 1761-1771.

Frydrych, K., Kowalczyk-Gajewska, K., 2018, Grain refinement in the equal channel angular pressing process: simulations using the crystal plasticity finite element method, Model. Simul. Mater. Sci. Eng., 26, 065015.

Frydrych, K., Kowalczyk-Gajewska, K., Prakash, A., 2019, On solution mapping and remeshing in crystal plasticity finite element simulations: Application to equal channel angular pressing, Model. Simul. Mater. Sci. Eng., 27, 075001.

Gambin, W., 1991, Plasticity of crystals with interacting slip systems, Enging. Trans., 39, 303-324.

Hill, R., Rice, J.R., 1972, Constitutive analysis of elastic-plastic crystals at arbitrary strain, J. Mech. Phys. Solids, 20, 401413.

Hosemann, P., Vieh, C., Greco, R., Kabra, S., Valdez, J., Cappiello, M., Maloy, S., 2009, Nanoindentation on ion irradiated steels, J. Nucl. Mater., 389(2), 239-247.

Hosemann, P., Kiener, D., Wang, Y., Maloy, S.A., 2012, Issues to consider using nano indentation on shallow ion beam irradiated materials, J. Nucl. Mater., 425(1-3), 136-139.

Hure, J., El Shawish, S., Cizelj, L., Tanguy, B., 2016, Intergranular stress distributions in polycrystalline aggregates of irradiated stainless steel, J. Nucl. Mater., 476, 231-242.

Korelc, J., 1996, Symbolic approach in computational mechanics and its application to the enhanced strain method, $\mathrm{PhD}$ thesis, Department of Mechanics, TH Darmstadt.

Korelc, J., 1997, Automatic generation of finite-element code by simultaneous optimization of expressions, Theoretical Computer Science, 187(1-2), 231-248.

Korelc, J., 2002, Multi-language and multi-environment generation of nonlinear finite element codes, Eng. Comput., 18, 312-327.

Korelc, J., Wriggers, P., 2016, Automation of finite element methods, Springer, Basel.

Kowalczyk, K., Gambin, W., 2004, Model of plastic anisotropy evolution with texture-dependent yield surface, Int. J. Plast., 20, 19-54.

Kucharski, S., Jarząbek, D., 2014, Depth dependence of nanoindentation pile-up patterns in copper single crystals, Metall. Mater. Trans. A, 45(11), 4997-5008. 
Kucharski, S., Stupkiewicz, S., Petryk, H., 2014, Surface pile-up patterns in indentation testing of $\mathrm{Cu}$ single crystals, Exper. Mech., 54(6), 957-969.

Lengiewicz, J., 2008, Analiza wrażliwości dla zagadnień kontaktowych z tarciem, PhD Thesis, IPPT PAN, Warszawa, (in Polish).

Lewandowski, M., Stupkiewicz, S., 2018, Size effects in wedge indentation predicted by a gradient-enhanced crystal- plasticity model, Int. J. Plast., 109, doi 10.1016/j.ijplas. 2018.05.008

Li, L., Shen, L., Proust, G., Moy, C.K., Ranzi, G., 2013, Threedimensional crystal plasticity finite element simulation of nanoindentation on aluminium alloy 2024, Mater. Sci. Eng.: A, 579, 41-49.

Ling, C., Tanguy, B., Besson, J., Forest, S., Latourte, F., 2017, Void growth and coalescence in triaxial stress fields in irradiated fcc single crystals, J. Nucl. Mater., 492, 157-170.

Liu, M., Lu, C., Tieu, K., Yu, H., 2014, Numerical comparison between berkovich and conical nano-indentations: Mechanical behaviour and micro-texture evolution, Mater. Sci. Eng. A, 619, 57-65.

Liu, M., Lu, C., Tieu, K., Peng, C.T., Kong, C., 2015, A combined experimental-numerical approach for determining mechanical properties of aluminum subjects to nanoindentation, Scientific reports, 5, 15072.

Liu, M., Lu, C., Tieu, K., Zhou, K., Peng, C.T., 2016, Indentation analysis of mechanical behaviour of torsion-processed single-crystal copper by crystal plasticity finite-element method modelling, Philosophical Magazine, 96(3), 261273.

Liu, Y., Wang, B., Yoshino, M., Roy, S., Lu, H., Komanduri, R., 2005, Combined numerical simulation and nanoindentation for determining mechanical properties of single crystal copper at mesoscale, J. Mech. Phys. Solids, 53 (12), 2718-2741.

Liu, Y., Varghese, S., Ma, J., Yoshino, M., Lu, H., Komanduri, R., 2008, Orientation effects in nanoindentation of single crystal copper, Int. J. Plast., 24(11),1990-2015.

Mandel, J., 1971, Plasticité classique et viscoplasticité, CISM course No. 97. Springer, Wien.

Nie, J., Liu, Y., Xie, Q., Liu, Z., 2018, Study on the irradiation effect of mechanical properties of RPV steels using crystal plasticity model, Nuclear Engineering and Technology, 2018.

Petryk, H., Stupkiewicz, S., Kucharski, S., 2017, On direct estimation of hardening exponent in crystal plasticity from the spherical indentation test, Int. J. Solids Struct., 112, 209221.

Renner, E., Gaillard, Y., Richard, F., Amiot, F., Delobelle, P., 2016,. Sensitivity of the residual topography to single crystal plasticity parameters in Berkovich nanoindentation on FCC nickel, Int. J. Plast., 77, 118-140.

Ryś, M. , 2016, Constitutive modelling of damage evolution and martensitic transformation in 3161 stainless steel, Acta Mechanica et Automatica, 10(2), 125-132.

Ryś, M., Skoczeń, B., 2017, Coupled constitutive model of damage affected two-phase continuum, Mech. Mater., 115, 115 .

Saleh, M., Zaidi, Z., Ionescu, M., Hurt, C., Short, K., Daniels, J., Munroe, P., Edwards, L., Bhattacharyya, D., 2016, Relationship between damage and hardness profiles in ion irradiated SS316 using nanoindentation-Experiments and modelling, Int. J. Plast., 86, 151-169.
Skoczeń, B., Ustrzycka, A., 2015, Radiation Damage Evolution in Ductile Materials, Springer International Publishing, Cham, 397-411.

Skoczeń, B., Ustrzycka, A., 2016, Kinetics of evolution of radiation induced micro-damage in ductile materials subjected to time-dependent stresses, Int. J. Plast., 80, 86-110.

Stupkiewicz, S., Lengiewicz, J., Korelc, J., 2010, Sensitivity analysis for frictional contact problems in the augmented Lagrangian formulation, Computer Methods in Applied Mechanics and Engineering, 199(33-36), 2165-2176.

Thomas Jr., J.F., 1968, Third-order elastic constants of aluminum, Physical Review, 175(3), 955.

Torres-Torres, D., Muñoz-Saldaña, J., Gutierrez-Ladron-de Guevara, L., Hurtado-Macías, A., Swain, M., 2010, Geometry and bluntness tip effects on elastic-plastic behaviour during nanoindentation of fused silica: experimental and FE simulation, Model. Simul. Mater. Sci. Eng., 18(7), 075006.

Wang, Q., Cochrane, C., Skippon, T., Wang, Z., Abdolvand, H., Daymond, M.R., 2019, Orientation-dependent irradiation hardening in pure $\mathrm{Zr}$ studied by nanoindentation, electron microscopies, and crystal plasticity finite element modeling, Int. J. Plast., 124, 133-154.;

Wang, Y., Raabe, D., Klüber, C., Roters, F., 2004 Orientation dependence of nanoindentation pile-up patterns and of nanoindentation microtextures in copper single crystals, Acta Mater., 52(8), 2229-2238.

Wang, Z., Zhang, J., ul Hassan, H., Zhang, J., Yan, Y., Hartmaier, A., Sun, T., 2018, Coupled effect of crystallographic orientation and indenter geometry on nanoindentation of single crystalline copper, Int. J. Mech. Sci., 148, 531-539.

Xiao, X., Chen, L., Yu, L., Duan, H., 2019a, Modelling nano-indentation of ion-irradiated FCC single crystals by straingradient crystal plasticity theory, Int. J. Plast., 116, 216231.

Xiao, X., Terentyev, D., Bakaev, A., Zinovev, A., Dubinko, A., Zhurkin, E., 2019b, Crystal plasticity finite element method simulation for the nano-indentation of plasma-exposed tungsten, J. Nucl. Mater., 518, 334-341.

Yao, W., You, J., 2017, Berkovich nanoindentation study of monocrystalline tungsten: a crystal plasticity study of surface pile-up deformation, Philosophical Magazine, 97(17), 1418-1435.

Zambaldi, C., Raabe, D., 2010, Plastic anisotropy of $\gamma$-TiAl revealed by axisymmetric indentation, Acta Mater., 58(9), 3516-3530.

Zambaldi, C., Yang, Y., Bieler, T.R., Raabe, D., 2012, Orientation informed nanoindentation of $\alpha$-titanium: Indentation pileup in hexagonal metals deforming by prismatic slip, $J$. Mater. Res., 27(1), 356-367.

\section{SYMULACJE TESTU INDENTACJI Z WYKORZYSTANIEM TEORII PLASTYCZNOŚCI KRYSZTALÓW I METODY ELEMENTÓW SKOŃCZONYCH.}

\section{Streszczenie}

Celem pracy jest przedstawienie pomyślnego wyniku symulacji zadania nanoindentacji. Opisano wykorzystane w symulacjach modele izotropowej sprężysto-plastyczności oraz sprężysto-plastyczności kryształów. Przedstawiono również sformułowanie 
kontaktu ze sztywną powierzchnią przybliżającą końcówkę indentera o kształcie ostrosłupa. Zaprezentowano zarówno krzywe naprężenie-odkształcenie uzyskane w symulacji testu rozciągania, jak i siła-zagłębienie, które otrzymano przy użyciu pojedynczego zestawu parametrów materiałowych. Uzyskano zadowalająca zgodności z eksperymentem. Wydaje się, że tego typu wyniki zostały zaprezentowane po raz pierwszy

Received: August 27, 2019

Received in a revised form: October 31, 2019.

Accepted: November 15, 2019. 